\title{
O SER THEMONIA NA AMAZÔNIA: DIS- CUSSÕES SOBRE IDENTIDADE E PERFOR- MANCE NO CENÁRIO DRAG DE BELÉM DO PARÁ
}

\author{
MANUELA DO CORRAL VIEIRA \\ UNIVERSIDADE FEDERAL DO PARÁ \\ BELÉM, PARÁ, BRASIL \\ MANUELACORRALV@YAHOO.COM.BR \\ MATHEUS HENRIQUE CARDOSO LUZ \\ UNIVERSIDADE FEDERAL DO PARÁ \\ BELÉM, PARÁ, BRASIL \\ MATTZHENRIQUE26@GMAIL.COM
}




\section{O SER THEMONIA NA AMAZÔNIA: DISCUSSÕES SOBRE IDENTIDA- DE E PERFORMANCE NO CENÁRIO DRAG DE BELÉM DO PARÁ}

Resumo: Este trabalho busca ampliar as discussões envolvendo identidade e performance sob uma perspectiva etnográfica no cenário drag da cidade de Belém do Pará. A pesquisa analisou as construções singulares das expressões drag themonia, a partir de diálogos com as questões de gênero e as experiências e usos do corpo como meio de manifestação do sujeito em esfera estética, social e política.

Palavras Chave: Amazônia; Drag; Gênero; Identidade; Performance.

\section{EL SER THEMONIA EN LA AMAZONIA: DISCUSIONES ACERCA DE LA IDENTIDAD Y DE LA PERFORMANCE EN EL ESCENARIO DRAG DE BELÉM DO PARÁ}

Resumen: Este trabajo busca ampliar las discusiones acerca de la identidad y de la performance en una perspectiva etnográfica del escenario drag de la ciudad de Belém do Pará. La pesquisa ha analizado las construcciones singulares de las expresiones drag themonia, a partir de los diálogos con las cuestiones de género y las experiencias y usos del cuerpo como medio de manifestación del sujeto en esfera estética, social e y política.

Palabras Clave: Amazônia; Drag; Género; Identidad; Performance.

\section{THE BEING THEMONIA IN THE AMAZON: DISCUSSIONS ABOUT IDENTITY AND PERFORMANCE IN THE DRAG SCENARIO OF BELÉM DO PARÁ}

Abstract: This research aims to broaden the discussions involving identity and performance from an ethnographic perspective in the drag scenario of the city of Belém do Pará. The research analyzed the singular constructions of drag themonia expressions, from dialogues with the gender issues and the experiences and uses of the body as a manifestation of the subject in aesthetic, social and political sphere.

Keywords: Amazônia; Drag; Genre; Identity; Performance. 


\section{INTRODUÇÃO}

A definição de drag possui diversas possibilidades de entendimento. Em um breve histórico, drag, como entendido na atualidade, está bastante ligado com a teatralidade em sua formação. No teatro grego, somente homens podiam atuar, por isso interpretavam também papéis femininos; no teatro Kabuki no Oriente, homens participavam de dramatizações com canto, dança, além de pinturas faciais que expressavam características bizarras presentes na representação de suas divindades, e também performavam em papéis femininos'.

Hoje, é possível argumentar que o fazer drag vai além de uma simples representação, é um ato marcado por diversas possibilidades estéticas de representação e expressão através de um processo performático artístico que utiliza ferramentas como a maquiagem, figurinos, acessórios e materiais diversos. As drags também são responsáveis por atuar, mesmo que inconscientemente, na desconstrução de entendimentos pré-estabelecidos sobre gênero. Entretanto, é necessário também entender que drag não é uma identidade de gênero, e sim um ato artístico complexo que pode ser realizado de diversas formas. Drag possui um caráter multifacetado, pois existem várias categorias que as diferenciam, seja por estética, performance, personalidade, habilidades, além de traços culturais associados diretamente a nacionalidade da drag (JACQUES; CARVALHO; 2018). Atualmente, várias categorias drag foram apreendidas da cultura norte americana, utilizando o próprio termo ainda em inglês para se identificar, essas formas de expressão podem ir desde o objetivo de apresentar uma "ilusão total" de feminilidade, a exemplo das fishy queens, até a mescla de elementos como a androginia e elementos do movimento genderfuck, com a intenção de representar algo que de forma alguma remeta a qualquer gênero, sendo simplesmente drag.

Autores como Judith Butler (2003), apontam que a performance drag apresenta subentendidamente a estrutura imitativa do gênero e sua condicionalidade, esta apresentada pela autora como uma heterossexualidade normatizadora: "No lugar da lei da coerência heterossexual, vemos o sexo e o gênero desnaturalizados por meio de uma performance que confessa sua distinção e dramatiza o mecanismo cultural da sua unidade fabricada"

1 Informações retiradas da matéria especial "Drag queens: a história da arte por trás de homens vestidos de mulher”, publicada no Portal G1. Disponível em: <https://goo. gl/fQYQVf> 
(BUTLER, 2003, p. 196). Assim como, também pode se entender a partir dos estudos sobre travestis de Miskolci e Pelúcio (2012), no qual é possível perceber que as drags também podem ser consideradas como "seres singulares produtores de diferença", pois, sua corporalidade e performance fazem parte de um grupo de "identidades não categorizáveis".

O presente trabalho objetiva empreender um estudo sobre o cenário drag no recorte regional da cidade de Belém do Pará. Neste sentido, é possível perceber particularidades que o cenário drag de Belém possui, este inserido no contexto da região amazônica e composto por indivíduos que atuam nas mais diversas formas, expressando diferentes performances e exibindo diferentes corporalidades. Um dos exemplos desta singularidade é o autorreconhecimento de um grupo de drags de Belém que se intitula como "themonias", cuja expressão performática e estética é marcada por características, inspirações e referências vindas do contexto amazônico o qual fazem parte. As themonias podem ser entendidas como uma das categorias drag mencionadas anteriormente, a identidade themonia é formada por características particulares de sociabilidade e dissidências que compõem a expressão artística, corporal e política de seus membros, a expressão dessa identidade representa a união do processo de rompimento de paradigmas já existentes no fazer drag sob uma perspectiva regional e de narrativas específicas. Contudo, vale ressaltar que existem outros tipos de drags em Belém, autorreconhecidas em outras categorias, sejam com denominações norte americanas ${ }^{2}$ ou não, ocupando e atuando em diferentes espaços, ainda que muitas vezes se encontrem devido a sua característica comum que é ser drag.

Com o olhar voltado especificamente sobre o grupo "themonias", buscamos despontar inquietações, sobretudo, acerca das proposições de Estevão Fernandes e Fabiano Gontijo (2017) em seu "Manifesto Queer Caboclo", no qual anseiam pela desnormativização dos métodos de pesquisa que partem de perspectivas coloniais sobre seus objetos de estudo, a fim de não mais corroborar para o silenciamento sistemático das narrativas singulares como as existentes no contexto regional, político, social, cultural e econômico da Amazônia.

Para a realização deste trabalho foi utilizada a etnografia, na qual foram 
feitas entrevistas com diferentes interlocutores por meio de roteiro semiestruturado de perguntas. Os interlocutores foram conhecidos a partir de levantamento de pré-campo do cenário drag, inicialmente acompanhando-os pelas redes sociais (principalmente o Instagram), e presenciando seu trabaIho artístico e performático em festas, palestras e encontros. Um dos autores também realizou pesquisa exploratória participativa, estando também inserido neste meio desde o início de 2018 , onde realiza sua performance drag como Madeusa Umbreon, inclusive se autorreconhecendo como themonia, o que auxiliou no contato com os interlocutores, além de ter possibilitado uma percepção maior das observações de campo devido a afinidade e a realização de atividades neste meio.

Os interlocutores que conduzirão as narrativas presentes neste estudo estão apresentados na tabela a seguir, com seu nome de registro e seu nome de drag, respectivamente, além de outras informações declaradas a partir de seu autorreconhecimento:

Tabela 1 - Apresentação dos interlocutores

\begin{tabular}{|l|l|l|l|l|}
\hline \multicolumn{1}{|c|}{ Nome } & \multicolumn{1}{c|}{ Idade } & \multicolumn{1}{c|}{ Gênero } & \multicolumn{1}{c|}{ Sexualidade } & \multicolumn{1}{c|}{ Cor } \\
\hline $\begin{array}{l}\text { Iveraldo Júnior } \\
\text { (Tiana Banks) }\end{array}$ & 23 & Indefinido & Indefinida & Negro \\
\hline $\begin{array}{l}\text { Juliana Bentes } \\
\text { (Luna Skyyssime) }\end{array}$ & 26 & Feminino & Indeterminada & Branca \\
\hline $\begin{array}{l}\text { Lucas Paixão } \\
\text { (Luka Cortez) }\end{array}$ & 26 & Masculino & Homossexual & Branco \\
\hline $\begin{array}{l}\text { Matheus Henrique } \\
\text { (Madeusa Umbreon) }\end{array}$ & 19 & Masculino & Homossexual & Branco \\
\hline $\begin{array}{l}\text { Rodrigo Sampaio } \\
\text { (Joe Hera) }\end{array}$ & 19 & Masculino & Homossexual & Branco \\
\hline
\end{tabular}

Fonte: Elaboração dos Autores

A partir dos interlocutores apresentados, sob uma perspectiva comunicacional, antropológica, social e política, este artigo inicialmente explora a construção da identidade drag themonia a partir das discussões sobre identidade e diferença de Tomaz Tadeu da Silva (2000). Em seguida, relacionamos os estudos da teoria Queer sob a ótica inicial de Judith Butler (2003), com a perspectiva pós colonial de Fernanda Belizário (2016) a fim de com- 
preender o caráter transgressor das convenções normatizadoras de gênero presentes no ato de fazer e estar e em drag, especificamente no contexto Amazônico. Além de utilizar a perspectiva comunicacional sobre performance de Adriana Amaral, Thiago Soares e Beatriz Polivanov (2018), para então poder apontar o corpo como cerne de uma discussão futura a ser seguida.

\section{A IDENTIDADE E A DIFERENÇA DAS THEMONIAS}

Mas afinal, o que constitui a identidade themonia? Por que esse debate se faz tão importante ao querer "particularizar" ou de fato diferenciar a identidade - ou categoria - da performance drag themonia de uma noção geral de drag? Da Silva (2000) levanta questionamentos que serão analisados aqui sob a perspectiva do cenário drag de Belém, como: "Quais as implicações políticas de conceitos como diferença, identidade, diversidade, alteridade? O que está em jogo na identidade?" (DA SILVA; 2000, n.p). Da Silva (2000) explica que em uma perspectiva positiva, a identidade, assim como a diferença, são autoreferenciadas, ou seja, são completas de significado em si mesmas, e simplesmente existem. Ambas são dependentes entre si e inseparáveis: "Isto reflete a tendência a tomar aquilo que somos como sendo a norma pela qual descrevemos ou avaliamos aquilo que não somos." (DA SILVA; 2000, n.p).

O autor coloca, assim, a diferenciação como o processo que dá origem tanto a identidade quanto a diferença. A produção de ambas parte de um contexto cultural e social ao qual estão inseridas, sendo produto de nossas relações com este contexto (DA SILVA, 2000). Entretanto, o pesquisador explica que elas não estão encerradas pelos sistemas discursivos e simbólicos que lhes dão definição, pois a própria linguagem entendida amplamente como forma geral de significação é instável. A construção da estética e performance drag está diretamente ligada ao processo de produção de identidade e diferença, pois estes indivíduos elaboram suas identidades - em outra perspectiva, sua diferença - a partir do contexto ao qual estão inseridos, como afirma Luna Skyyssime sobre seu âmbito de socialibidade: "Pra mim a Luna muito mais do que uma coisa corporificada, é um justamente um debate, a Luna é um debate do meu dia a dia, do meu corpo, do meu local, do meu espaço como mulher, como LGBT naquele ambiente." (Luna Skyyssime em entrevista de campo realizada por ocasião desta pesquisa).

Durante a entrevista de campo, Luna explicou como funciona o seu processo de construção de performances, nesse caso entendidas como 
apresentações com dublagem e/ou dança e coreografia. Segundo ela, essas performances costumam apresentar coisas que atravessam o seu dia a dia, que a tocam sentimentalmente e que ela então sente que sua voz pode ser ecoada através de uma música, um texto, um poema ou pelo seu próprio corpo. Nesse sentido, as performances de Luna Skyyssime na cidade costumam já ser reconhecidas pelo seu viés de militância política, temática que costuma aparecer bastante em suas apresentações, como ela explica:

\begin{abstract}
A partir do momento em que a militância e o entendimento pela causa (LGBTI+) entrou na minha vida, quando eu comecei a entender esses debates todos, se tornou algo que eu precisava também falar, também cabia no meu corpo debater aquilo, então acabou se voltando mais pra esse viés. Até porque eu era sempre a única mulher, então se tornou necessário ter alguém falando sobre as causas de mulheres ali na frente, até hoje $90 \%$ das vezes quando tem performances eu sou a única mulher, então geralmente eu tô falando sobre o que é ser uma mulher dentro daquele espaço, como eu estou me sentindo nele, de que forma meu corpo vai reagir ali, que mensagem eu quero passar pras pessoas. (Luna Skyyssime em entrevista de campo realizada por ocasião desta pesquisa)
\end{abstract}

Já Luka Cortez realizou em 2018 uma série de montações ${ }^{3}$ que carregavam esteticamente e conceitualmente um conjunto de referências presentes em Belém do Pará, na Amazônia, e apresentava performances que refletiam não só a sua unicidade enquanto indivíduo, mas também os aspectos coletivos presentes na região em que vive por meio de sua drag, a exemplo de sua performance em homenagem ao Mercado de São Brás, patrimônio da cidade de Belém, e que integra o bairro onde Luka, o próprio Lucas, vive.

3 Trata-se de um termo comum no meio drag, refere-se ao conjunto material que representa o "estar em drag”, em suma, as roupas, acessórios, maquiagens, objetos e materiais utilizados pela drag. 
Imagem 1 - Luka Cortez representando a memória do Mercado de São Brás

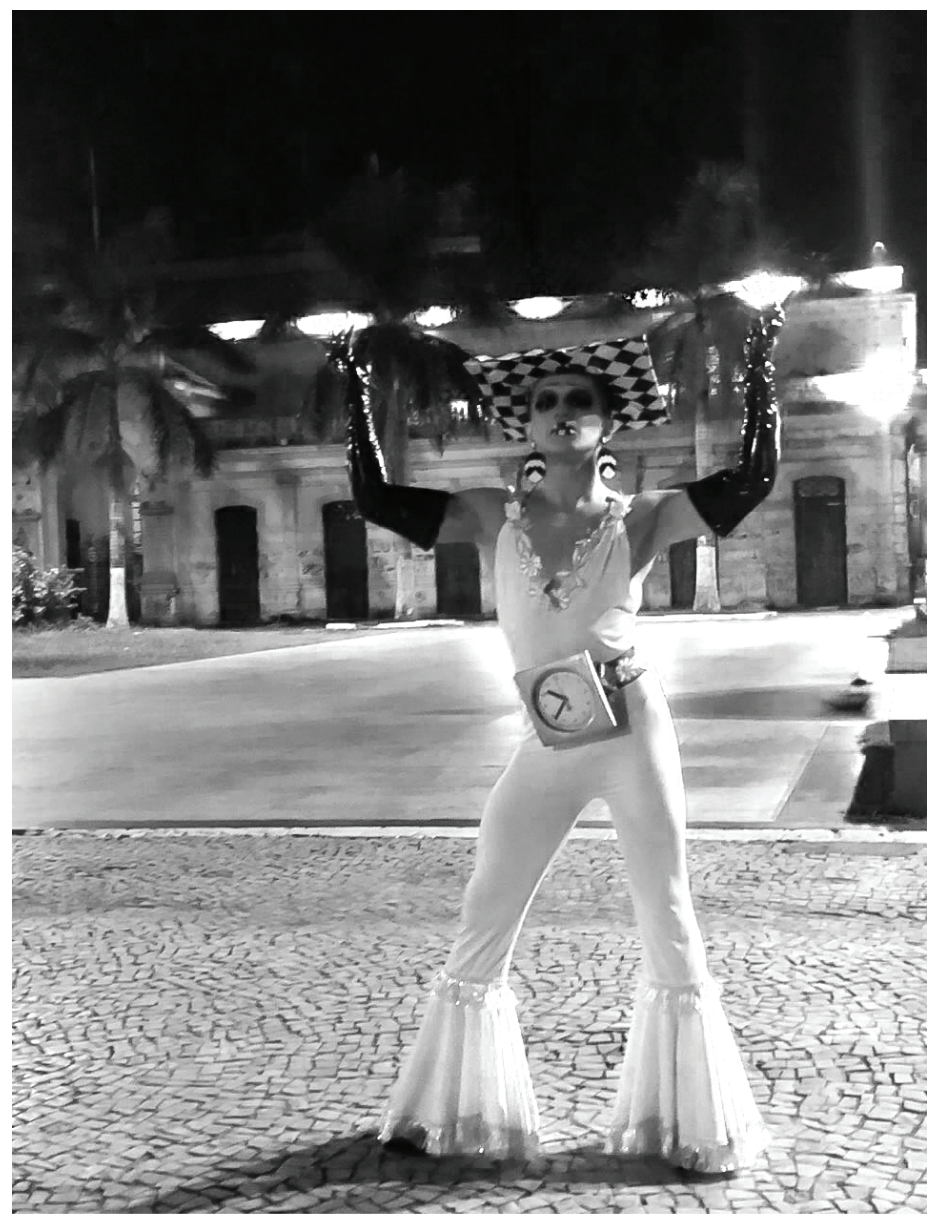

Fonte: Instagram (@cortezluka)

Da Silva (2000) situa a linguagem como diretamente ligada a construção da identidade e da diferença, ao que ambas "são tão indeterminadas e instáveis quanto a linguagem da qual dependem" (DA SILVA, 2000, n.p). Nesta perspectiva, pode-se assumir que as formas de linguagem, especialmente a linguagem corporal, é o que dá significado a identidade drag. É necessário frisar que a identidade e a diferença se constroem no meio social, e por isso estão sujeitas aos sistemas de poder vigentes na sociedade em questão, na qual ambas são condicionadas (DA SILVA, 2000). A comunidade LGBTI+ que majoritariamente compõe o cenário drag, não só de Belém, foi condicionada a ser o "diferente", ao que são marginalizados por sua sexualidade e gênero, não obstante também a discriminação quanto sua performance drag, vista como ainda mais divergente do cânone artístico aceito socialmente.

Percebe-se também a existência de determinados guias sociais estéticos, artísticos e performáticos que apontam para o que é socialmente aceito, situado na heteronormatividade que regula também a aceitação da 
arte, indicando e delimitando normas que vão desde o aspecto estético a ser apresentado quanto ao direito de produção de quem intenta realizá-la, o que culmina, sobretudo, no apagamento social e marginalização de indivíduos que distanciam-se da norma. Nesse ínterim, o fazer drag em geral apresenta seu caráter divergente aos padrões socialmente apresentados, a se ver por seus realizadores serem, em geral homens, mas também com a expressiva presença de mulheres, seja cisgênero ou transgênero, e em sua maioria LGBTI+, sujeitos que agora começam a ocupar novos espaços e também reivindicam sua visibilidade e reconhecimento no âmbito artístico, através de suas expressões e manifestações que se opõe, sobretudo, ao propósito da arte heteronormativamente aceita.

Todavia, a partir do momento em que o fazer drag se encontra definido, mesmo que transitoriamente, em um ponto comum geral, ou seja, cria sua identidade, é possível separar a partir desta, outros processos de diferenciação que derivam do inicial. Nesse âmbito, percebe-se inclusive as diversas categorias drags já mencionadas, mas aqui enfatiza-se as themonias como um exemplo de grupo que se situa como "diferente", pois faz parte do grupo drag, ou seja, da identidade geral como drag, mas que devido suas peculiaridades, suas características próprias, se estruturaram em um grupo novamente diferente, as themonias, e que agora desenvolve e autorreconhece sua própria identidade.

Da Silva (2000) afirma que há uma disputa pela identidade, a qual menciona como um embate entre grupos sociais distintos situados em diferentes hierarquias de poder. "A afirmação da identidade e a enunciação da diferença traduzem o desejo dos diferentes grupos sociais, assimetricamente situados, de garantir o acesso privilegiado aos bens sociais" (DA SILVA; 2000, n.p). Neste embate, o autor também situa as implicações vinda a partir afirmação da identidade e da diferença, como as declarações de pertencimento e não pertencimento, inclusão e exclusão: "Os pronomes 'nós' e 'eles' não são, aqui, simples categorias gramaticais, mas evidentes indicadores de posições-de-sujeito fortemente marcadas por relações de poder." (DA SILVA, 2000, n.p).

A partir da consideração entre afirmação e identidade (e diferença), principalmente pelo viés político de sua implicação, é possível debater a questão da nomenclatura themonia, a qual apesar de soar como um trocadilho a palavra demônia, não é estritamente ligada aos elementos sombrios ou demoníacos que se supõe ao ouvi-la, aproximando-se mais de uma indefinição 
que singulariza o grupo de drags que se autodenomina como themonia. A apropriação de um termo, seguida de sua reformulação, não só escrita mas de seu significado, já torna evidente o ensejo por possuir uma identidade, uma nomenclatura que os demarque enquanto grupo, por isso, essa autoafirmação em muito contribui para a visibilidade da diferença das drags themonias, pois os aproxima por suas semelhanças e objetivos em comum, assim como demarca seu espaço enquanto indivíduos únicos e residentes da amazônia. Ademais, é importante explicitar que apesar deste processo delimitar marcadores de distinção enquanto particularidades, o grupo ou categoria de drags themonias possui um amplo universo de sociabilidade no qual acolhe e convive com todo tipo de drags, seja de maneira fixa ou transitória.

\section{ENTENDENDO O FAZER/ESTAR EM DRAG}

Para entender melhor a discussão que cerca o fazer drag, especialmente sobre as themonias, faz-se necessário delinear certos entendimentos referentes aos estudos de Butler (2003), para então ser possível articular considerações sob a perspectiva das narrativas dos interlocutores aqui apresentados. Segundo a autora (2003), os gêneros, masculino e feminino, tratam-se de performances realizadas pelos indivíduos, empreendidas sob uma norma que delimita expressões estéticas, comportamentos, papéis sociais, entre outras configurações dicotômicas que separam o masculino do feminino, e que não por acaso elegem o primeiro como superior, eis então a ordem da heteronormatividade que rege e gerencia as articulações de poder político e social. Sob a concepção da filósofa americana, estar em drag é uma das possibilidades performativas do próprio gênero, porém, não sendo em si um gênero, e sim um ato imitativo que desestrutura a coerência heteronormativa em vigor. Essa característica transgressora presente no drag se deve ao fato deste "brincar" com os elementos estéticos e comportamentais delimitados aos dois gêneros, os interligando, cruzando, subvertendo, e por fim, os expressando por meio de uma construção artística singular em seu corpo e comportamento.

Ademais, classificar drag como uma expressão artística nos guia para um outro âmbito de debate, no qual é possível traçar considerações acerca de seu entendimento enquanto arte e o desenvolvimento de suas potencialidades enquanto experiência artística. Por isso, partimos das concepções de Marcos Villela Pereira (2012), que aponta para a "possibilidade da consti- 
tuição da obra de arte a partir da experiência estética com objetos e acontecimentos não artísticos, ou seja, não enquadrados nos cânones do que se considera arte, seja em que esfera for" (PEREIRA, 2012, p. 191). Além disso, o autor ainda classifica a constituição de tal experiência como uma realização que parte tanto do artista quanto do público. Assim, o que seria o fazer drag senão uma construção que se desenvolve nesse ínterim? É possível perceber em campo que a experiência drag, aqui com o foco nas themonias, se constitui justamente da transfiguração de objetos já existentes em um outro contexto, com um outro apelo, os quais a partir do corpo da drag são ressignificados desde sua funcionalidade até sua exposição.

Tendo como palco da experiência estética e artística o corpo, não é possível desvinculá-lo de seu contexto social e político, ao que utilizamos a perspectiva de Lúcio Costa da Silva Girotto et al (2017) para entender que em estudos queer, situados nas questões de gênero e corporeidades, é preciso abandonar a neutralidade, na medida em que "exige-se uma implicação analítica ao corpo do pesquisador, já que o mesmo não está fora dessas relações de forças, de scripts narrativos, mas, ao contrário, mergulhado no meio destas, permeado pelas mais diversas realidades e corporeidades" (GIROTTO et al, 2017, p. 96). Assim como Girotto (2017), consideramos a prática drag também como um manifesto estético por sua potência transgressora diante das construções de gênero e da formação do próprio corpo.

Pereira (2012) afirma que é possível entender a arte como uma "experiência singular e subjetiva que pode bem ser individual ou coletiva, mas que definitivamente vai na direção da singularidade. E a singularidade, nesse caso, tanto pode ser a do artista quanto a do crítico ou, ainda, a do espectador" (PEREIRA, 2012, p. 184). O autor também aponta que independente da natureza da obra de arte, ela representa uma zona de confluência de possibilidades, por isso, um acontecimento artístico não existe para ser simplesmente compreendido ou dominado, mas para ser experimentado.

As possibilidades que surgem com o fazer drag permitem que não somente estas, mas também o público que assiste e interage, ambos possam vivenciar e experimentar novas formas de expressões e sentidos, além de propagar o viés de manifesto político inerente ao fazer drag, possibilitando a visibilidade de indivíduos LGBTI+ e sua resistência à heteronormatividade existente na sociedade que tende ao silenciamento de sua existência. Contudo, é necessário perceber que os aspectos analisados acima sobre o fazer/estar em drag ainda não são suficientes para se compreender as arti- 
culações de gênero e poder no contexto do recorte regional estudado aqui, localizado especificamente em Belém do Pará, situado na região norte do Brasil e inserido também na região amazônica, onde as configurações sociais derivam de um processo histórico de colonialismo nacional, onde em muitos aspectos ainda persiste o apagamento das identidades e expressões nativas, em especial da região amazônica brasileira, na qual ainda se perpetuam sistemas de dominação social, política, econômica, racial e regional, os quais ainda também se somam as problemáticas relacionadas a gênero e sexualidades, bem como sua relação com outros marcadores sociais da diferença.

Por isso, é importante explicitar a importância dos estudos de Butler (2003) para se ter como base um estudo consolidado, sobretudo, das questões envolvendo os seres que transgridem a normatividade, apresentados como queer, aliado a apropriação do viés artístico de Pereira (2012) para situar a expressão drag como arte, somado a perspectiva de Girotto et al (2017) ao traçar linhas que apontam para a "percepção da finitude de teorias e corpos, possibilitando inventar e arquitetar empatias afetivas por corpos-teorias-outras e suas tramas singulares e territorialidades" (GIROTTO et al, 2017, p. 108). Ademais, também somar a este raciocínio a visão de Belizário (2016), na qual afirma que "talvez a radicalidade última do encontro do queer com o pós-colonial seja o corpo. O corpo como limite, o corpo que provoca afetos e é afetado pela identidade, pelos sujeitos, pelas opressões, pelas diferenças, pelas fronteiras e pela tradução" (BELIZÁRIO, 2016, p. 391), e assim podemos situar aqui o corpo como a principal discussão a ser colocada para se entender as problemáticas de gênero, performance e identidade sob a narrativa do fazer drag themonia.

\section{DISCUTINDO PERFORMANCE DRAG}

Para se compreender a construção de uma performance é necessário "abrir-se para o ato, a ação, o cênico. Aquilo que se faz, como se faz, em que contexto." (AMARAL et al; 2018, p. 64). Adriana Amaral, Thiago Soares e Beatriz Polivanov (2018) percorrem em sua obra por diferentes perspectivas de estudos sobre performance, as quais serão relevantes para a construção do raciocínio deste trabalho, onde pretendemos situar a performance drag em tais visões. Neste sentido, performance é tida como um modo de conhecer fenômenos, ao que também compreendem-se linhas metodológicas: “A premissa da autora parece ser a de pensar a performance como um imbri- 
camento entre as linguagens e suas encenações, as situações e contextos de aparições e as dinâmicas de visualidade e fruição" (AMARAL et al; 2018, p. 66). Assim, depreende-se que os estudos sobre performance requerem métodos próprios diante das especificidades dos seus objetos, sendo assim um estudo interdisciplinar. Sob esta ótica é possível situar a performance drag em seu processo de construção, o qual surge a partir das mais variadas experiências e referências a que estão sujeitos os seus realizadores, como se pode perceber na fala da drag Luka Cortez:

Ser drag pra mim é pegar nossas trocas de experiências, vivências no nosso meio, nossos gostos, experiências boas e ruins, se apropriar de objetos, coisas e lugares e transformar isso em arte drag. Isso não envolve materiais, perucas, maquiagem, ser homem ou ser mulher, trans, travesti, cor, isso envolve ser acima de tudo. Fazer drag é pegar o seu eu, o eu dos outros, a sua relação com o eu dos outros, o ambiente que você vive, o que você gosta, o que você consome, pegar o que você quiser pegar, jogar no seu corpo e transformar na sua drag. (Luka Cortez em entrevista de campo realizada por ocasião desta pesquisa)

A performance de Luka, assim como a de outras drags themonias, estão imbricadas neste processo de sociabilidade que se inicia individualmente e se expande com as relações interpessoais e com o meio em que vivem. As relações e manifestações empreendidas no contexto drag amazônico se organizam a partir do momento em que seus interlocutores compartilham não só de impulsos e desejos comuns, mas também dividem um contexto político e geográfico permeado por dificuldades exclusivas, mesmo que suas condições socioeconômicas ainda se diferenciem em determinados pontos, suas vivências enquanto LGBTI+ e membros da comunidade drag em Belém se cruzam.

Alguns exemplos dessas relações podem ser vistos a partir de montações como a de Luka Cortez no desfile performático "Amazônia Drag”, no qual a drag aparece representando a leitura de um livro popular chamado "Visagens e Assombrações de Belém”, no qual mescla toda sua influência dark e sombria em uma caracterização drag que remete a um aspecto popular da cultura paraense, representados as "visagens" presentes na cultura amazônica (ver imagem 2). Assim como a montação de Juliana Bentes, ou Luna Skyyssime, para sua qualificação de mestrado, a qual apresentou a pesquisa "montada" com cores, traços e acessórios que representavam não só a 
floresta amazônica, mas o seu papel desenvolvendo conhecimento no meio acadêmico (ver imagem 3), como a própria afirma em entrevista:

O tema (da dissertação) é a territorialidade, ou seja, esse território subjetivo que a gente constrói, o território físico e subjetivo da cidade de Belém, e como esses territórios agem na construção dos processos criativos das 'demônias' (...). Eu fui de verde escuro porque o trabalho retrata isso: é mata virgem, mata fechada, é território não explorado na academia ainda, e que a gente vai desbravando aos pouquinhos. (Luna Skyyssime em entrevista para o jornal O Liberal)4.

Imagem 2 - Luka Cortez representando as "visagens" de Belém

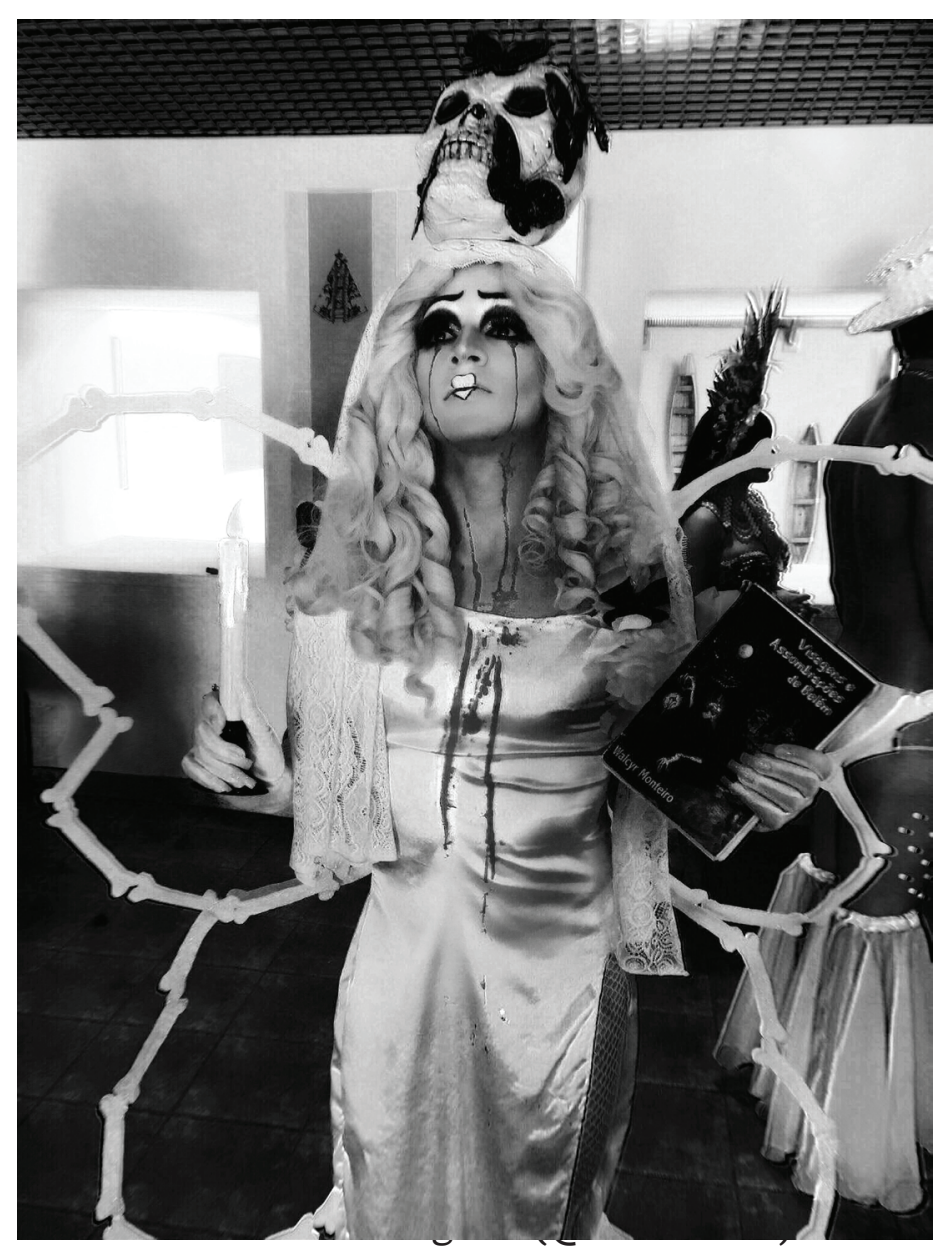

Imagem 3 - Luna Skyyssime durante a defesa de sua dissertação de mestrado sobre 


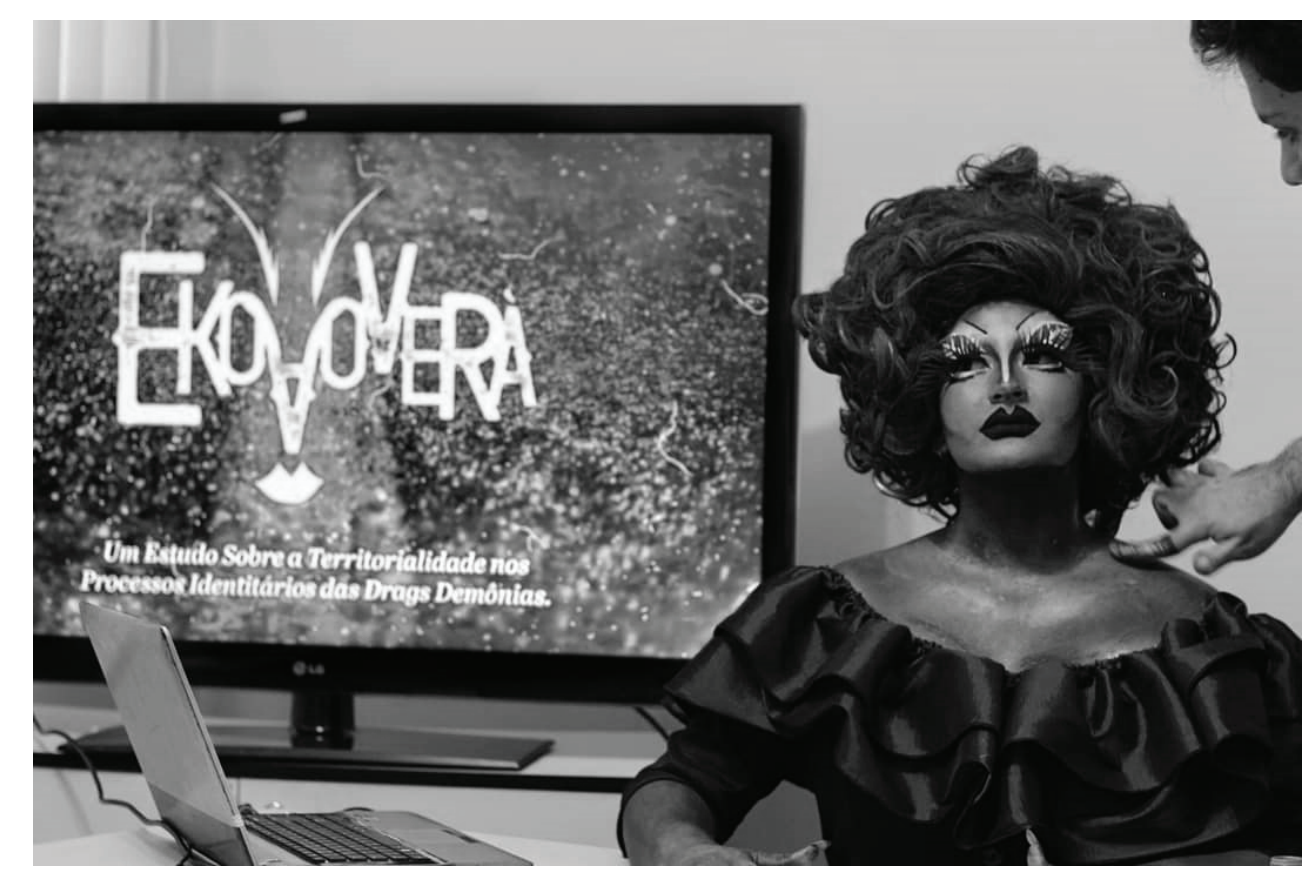

Somado a esta perspectiva, os autores também atribuem as noções de Victor Turner ao associar a performance com as possibilidades de desdobramentos políticos das interpretações e aos desejos de acesso dos sujeitos (AMARAL et al; 2018, p. 66). Assim, a performance drag se situa em termos dessa interpretação cultural, haja vista que historicamente não se tem registros sobre quaisquer ancestralidade amazônica que viesse a originar o fazer drag existente na atualidade, mas tal prática veio a ser incorporada na contemporaneidade, onde no recorte específico desta pesquisa é possível perceber claramente a recepção e execução desse ato performático conhecido como drag, mas que é interpelado pelas interpretações próprias do âmbito regional socioeconômico político em que são executadas, ao que situamos a fala da drag Tiana Banks:

Eu conhecia as drags mas não sabia exatamente o que era, pra mim travesti e drag eram tudo a mesma coisa, só quando eu comecei a assistir RuPaul's a minha cabeça abriu mais sobre isso. (...) Eu acho que a gente não tem tantos recursos, acho que pra elas de fora é mais fácil, elas têm mais acesso, maquiagens melhores. Claro que a gente se adapta a tudo, né? A nossa principal diferença é a adaptação. (Tiana Banks em entrevista de campo realizada por ocasião desta pesquisa).

O posicionamento de Tiana Banks aponta para o aspecto da midiatiza- 
ção da arte drag, ao que se refere principalmente sobre a atual influência do reality show RuPaul's Drag Race 5 e reúne drags de diferentes estilos, entretanto levanta bastante discussões quanto a normativização e exaltação de determinados tipos de drag durante o programa ${ }^{6}$. Para além do programa, podemos citar também a drag brasileira cantora e compositora Pabllo Vittar, que já ganhou o Prêmio Multishow ${ }^{7}$ de Música Brasileira e outros prêmios nacionais, além de ter sido indicada ao Grammy Latino e ao MTV Europe Music Awards.

Tanto RuPauls's Drag Race quanto Pabllo Vittar são dois grandes nomes da atualidade que representam massivamente a arte drag na mídia, sendo também em grande parte a influência de uma nova geração de drags que surge. $O$ que ambas possuem em comum é principalmente o referencial estético, haja vista que, sobretudo o reality, acaba por propagar determinados padrões de estilo drag, estes muito semelhantes ao que vemos em Pabllo Vittar. Essa difusão de padrões é perceptível principalmente através dos discursos do programa, que tendem a exaltar os estilos de drag mais femininos e a estranhar e se distanciar mais de estilos que utilizam outras concepções em seu desenvolvimento, mas o programa aos poucos parece mudar seu discurso e assim contribuir para uma aceitação maior da infinitude de estilos drag. Assim, a fala de Tiana representa a diferença no processo de construção da identidade themonia, ainda que esta não esteja completamente isenta da influência das grandes referências drags midiatizadas, pois o processo de desenvolvimento de uma performance themonia perpassa por diferentes fronteiras e ainda é fortemente ligado aos processos de sociabilidade que as constitui, o que é poderia ser considerado até mesmo como uma subversão da subversão" um processo naturalmente desnormativizador, mas que não encerra ali, e está longe de se consolidar em uma definição acabada.

Ademais, um dos apontamentos presentes no trabalho de Adriana Amaral, Thiago Soares e Beatriz Polivanov (2018) é a das "traduções possíveis" de performance no contexto da América Latina de Taylor (2003), sendo es-

5 Programa de televisão estadunidense que reúne drag queens em uma competição para coroar a nova American Next Drag Superstar, o reality consiste em desafios como atuação, costura, coreografia, dublagem, entre outros, visando assim escolher a queen mais completa e que contemple os requisitos "Charisma, Uniquiness, Nerve and Talent".

6 Ver mais em: JACQUES, Jackson; CARVALHO, Maria Luiza. I am the future of drag: A drag mal interpretada em Rupaul's Drag Race. Temática, 2018, 14.2.

Canal de televisão brasileiro. 
tas fruto dos debates francófono e anglo saxão ainda inacabados (AMARAL et al; 2018). A principal tradução a que recorro para esta análise é a de representação, pois esta traduz um dos principais âmbitos da performance drag, cujo caráter mimético que possui é responsável por executar o processo de rompimento entre a realidade e a forma como está é representada, ao que é exemplificada pela colocação de Luka Cortez: "A cultura drag consegue assimilar tudo e transformar em drag, por exemplo, às vezes pegar uma palavra, um conceito, um objeto, uma casa, uma fruta e transformar em algo para vestir, para ser" (Luka Cortez em entrevista de campo realizada por ocasião desta pesquisa). Sendo esse processo inserido na esfera política de pertencimento e visibilidade de um grupo social, haja vista que os indivíduos que o realizam, ao o fazerem estão, mesmo que inconscientemente, rompendo com a "realidade" não só das noções de gênero mas das "coisas" e do corpo em si, ao que é possível colocar em questão o processo de "montação" da drag Luna Skyyssime:

\begin{abstract}
Eu gosto muito de trabalhar com materiais não usuais, principalmente itens de papelaria, clips, grampos, papel, pregos, folhas, penas, pedras, palitos de dente, tudo eu já colei na cara. Isso quebra não só o formato do rosto, quebra a organicidade daquilo, é totalmente anti-orgânico e é muito importante levar isto para o debate, o que foge totalmente do humano. Isso também amplia infinitamente o debate sobre drag. (Luna Skyyssime em entrevista de campo realizada por ocasião desta pesquisa).
\end{abstract}

A partir desse ponto, é possível perceber que para analisar a performance drag é preciso ter como foco, sobretudo, o corpo em contato com as materialidades como motor da produção de sentido, pois é nele que o ato performático se concretiza. Pode se inferir que o ato performático drag é fruto não somente da intencionalidade de quebra da conceituação de gênero, mas possui muitas outras camadas em sua composição, todas vindas da fusão entre subjetividade e materialidade. Trata-se de um processo em constante construção, como afirma Amaral et al (2018):

Ainda que certos atos performáticos e seus registros - como shows de música e apresentações teatrais - possam trazer uma ideia de término ou conclusão dos mesmos, eles não se encerram em si mesmos, causando afetações, reverberações e reelaborações mesmo após seu suposto fim e que certamente se iniciam antes de seu começo. O motor da vida, da performance, não cessa. 
Em determinado ponto da pesquisa realizada por Amaral et al (2018), os autores articulam performance na relação entre comunicação e música, porém, apropriamos aqui algumas dessas considerações para dialogar com a performance drag, de modo que também a situamos em um dos percursos metodológicos apontados, sendo aquele "que evoca uma articulação de performance como memória, como política identitária de grupo ou da singularidade de sujeitos, ou diante de políticas da visibilidade (o que se registra, quem registra, com quais propósitos)" (AMARAL et al; 2018, p. 71).

Esses aspectos são perceptíveis ao explorarmos as temáticas das performances que são realizadas pelas themonias, como por exemplo: o desfile da drag Joe Hera durante o Desfile Performático Amazônia Drag, no qual representava a Mãe das Águas, evocando uma divindade muito conhecida na cultura amazônica; a performance de Madeusa Umbreon em uma releitura da lenda da Rasga Mortalha em que mesclava os elementos do mito com as características festas de aparelhagem que ocorrem em Belém; a performance de Luka Cortez que resgata a memória do Mercado de São Brás e aponta o descaso governamental ao que o local se encontra; as performances de Luna Skyyssime que levantam a questão do empoderamento feminino, inclusive sobre o fato desta ser uma mulher cis em drag, fato que ainda pode ser considerado um tabu, haja vista o número reduzido de mulheres que fazem drag em Belém e até mesmo no Brasil.

Além disso, apontam-se outras performances realizadas em festas ou em eventos acadêmicos, mas que em sua realização evocam o olhar para as pautas políticas e sociais que fazem parte da vida tanto de quem as executa quanto de quem as assiste, seja incentivando a luta por direitos, seja tentando conscientizar as pessoas de suas reivindicações ou vivências, ou mesmo celebrando suas vidas e afirmando suas identidades, seus grupos, sua diversidade, seu espaço, ao que "abrem-se caminhos para se pensar singularidades nas formas com que as culturas teatralizam as experiências performáticas nas mídias e sobretudo aquilo que parece estar excessivamente circunscrito a um contexto" (AMARAL et al; 2018, p. 76).

\section{CONSIDERAÇÕES}

Este trabalho pretendeu dar continuidade a um estudo sobre o cenário drag de Belém do Pará, tendo como o foco deste artigo o grupo chamado 
de themonias. A etnografia realizada somada com o suporte teórico permitiu a realização de análises que puderam delinear um entendimento mais aprofundado acerca da construção da identidade, performance, questões de gênero e debates decoloniais que cercam as drags themoniais. As análises feitas nesta pesquisa abriram novas perspectivas de estudo e levantaram novos questionamentos que devem render contribuições cada vez mais completas sobre o objeto em questão.

Portanto, apontamos alguns percursos a serem seguidos futuramente como parte integrante do estudo maior ao qual este trabalho faz parte, a começar por uma análise que tenha como base fundamentadora a relação do corpo como palco da execução artística e performática drag, este como dispositivo intersectional situado em fronteiras, focando sempre neste mesmo recorte regional sociopolítico. Além disso, mostrou-se importante também realizar um estudo que possa perceber o papel da mídia como ferramenta de consumo e de construção de identidades e sociabilidades, assim como também buscar compreender de maneira prática as implicações políticas que o fazer drag realiza na sociedade.

\section{REFERÊNCIAS}

AMARAL, Adriana; SOARES, Thiago and POLIVANOV, Beatriz. Disputas sobre performance nos estudos de Comunicação: desafios teóricos, derivas metodológicas. Intercom, Rev. Bras. Ciênc. Comun. [online]. 2018, vol.41, n.1, pp.63-79. Disponível em: <http://dx.doi. org/10.1590/1809-5844201813>. Acesso em: 10 dez. 2018.

BELIZÁRIO, Fernanda. Por uma teoria queer pós colonial: colonialidade de gênero e heteronormatividade ocupando as fronteiras e espaços de tradução. In: Género, direitos humanos e ativismos: Atas do V Congresso Internacional em Estudos Culturais. Grácio Editor, 2016. p. 385-391. Disponível em: <https://goo.gl/7aTgJA >. Acesso em: 25 out. 2018. BUTLER, Judith. Problemas de Gênero: Feminismo e Subversão da Identidade. Rio de Janeiro: Civilização Brasileira, 2003.

DA SILVA, Tomaz Tadeu. A produção social da identidade e da diferença. In: Identidade e diferença: a perspectiva dos estudos culturais. Petrópolis: Vozes, 2000. Disponível em: $<$ https://goo.gl/6pN5Xz >. Acesso em: 13 jan. 2019.

FERNANDES, Estevão Rafael; DE SOUZA GONTIJO, Fabiano. Diversidade Sexual e De Gênero e Novos Descentramentos: Um Manifesto Queer Caboclo. Amazônica-Revista de Antropologia. Edição 8.1: p. 14-22. 2017. Disponível em: <https://goo.gl/pUEcmH >. Acesso em: 22 dez. 2018.

JACQUES, Jackson; CARVALHO, Maria Luiza. I am the future of drag: A drag mal interpretada em Rupaul's Drag Race. Temática, 2018, 14.2. Disponível em: <https://goo.gl/u1Tvp9>. Acesso em: 10 dez. 2018. 
GIROTTO, Lúcio Costa; DA SILVA, Cristiane Gonçalves; GARCIA, Maurício Lourenção. Experimentação de um dispositivo-corpo em uma vivência drag: pesquisar pelo afetar. Revista Periódicus, 2017, 1.6: 95-109. Disponível em: <https://goo.gl/fbNhxW>. Acesso em: 15 nov. 2018.

MISKOLCI, Richard; PELÚCIO, Larissa. Fora do sujeito e fora do lugar: reflexões sobre performatividade a partir de uma etnografia entre travestis. Revista Gênero, 2012, 7.2. Disponível em: <https://goo.gl/SHAf51>. Acesso em: 23 out. 2018.

PEREIRA, Marcos Villela. O limiar da experiência estética: contribuições para entender um percurso de subjetivação. Pro-Posições (UNICAMP. Impresso), 2012. Disponível em: <https://goo.gl/jTkdjN>. Acesso em: 13 out. 2018. 


\section{Manuela do Corral Vieira}

Doutora em Antropologia pela Universidade Federal do Pará (UFPA) e professora na Faculdade de Comunicação (FACOM) e no Programa de Pós-Graduação em Comunicação, Cultura e Amazônia (PPGCom) da UFPA. Líder do Grupo de Pesquisa Comunicação, Consumo e Identidade - CONSIA (CNPq/ UFPA).

E-mail: manuelacorralv@yahoo.com.br

\section{Matheus Henrique Cardoso Luz}

Graduando em Comunicação Social pela Universidade Federal do Pará (UFPA). Integrante do grupo de pesquisa Comunicação, Consumo e Identidade (CONSIA). Bolsista de Iniciação Científica pela Fundação Amazônia Paraense de Amparo à Pesquisa (FAPESPA).

E-mail: mattzhenrique26@gmail.com 